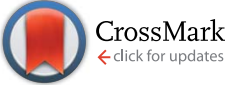

Cite this: RSC Adv., 2016, 6, 98737

Received 13th August 2016

Accepted 8th October 2016

DOI: $10.1039 / c 6 r a 20455 d$

www.rsc.org/advances

\section{Pectinases immobilization on magnetic nanoparticles and their anti-fouling performance in a biocatalytic membrane reactor $\dagger$}

\author{
Abaynesh Yihdego Gebreyohannes, ${ }^{a}$ Rosalinda Mazzei, ${ }^{a}$ Teresa Poerio, ${ }^{a}$ \\ Pierre Aimar, ${ }^{b}$ Ivo F. J. Vankelecom ${ }^{c}$ and Lidietta Giorno*a
}

Enzyme immobilization on commercial superparamagnetic nanoparticles ( $N P^{S P}$ ) was performed using covalent bonding. The biofunctionalized $N P^{S P}$ was then immobilized on the surface of the membrane using an external magnetic field to form a magneto-responsive biocatalytic membrane reactor (BMR ${ }^{\mathrm{SP}}$ ). The magnetically formed smart nanolayer can be easily re-dispersed and recovered from the membrane when the enzyme is deactivated or whenever cleaning is required due to substrate over-accumulation. The system was used to hydrolyze pectin contained in different streams. Results are supported with complementary data from hydrodynamic, kinetic and morphological characterization in a flow-through reactive filtration. Wavelength-dispersive $X$-ray spectroscopy (WDS) elemental mapping revealed that the $N P^{S P}$ are uniformly dispersed on the surface of the membrane forming a thin biocatalytic layer. Both results of hydrodynamic studies and SEM micrographs of the membrane with the enzyme layer under various operating conditions, show that the immobilized enzyme effectively reduced membrane-foulant interaction. Comparison of filtration data using this commercial NPS reveals good agreement with our previously used home-made NPS. This implies that the scaling-up and commercialization of the developed $\mathrm{BMR}^{\mathrm{SP}}$ can be straightforward.

\section{Introduction}

Bionanocomposites represent an emerging group of bioinspired and biomimetic nanostructured hybrid materials that take the advantage of organic and inorganic moieties. ${ }^{1}$ They are formed by the hybridization of natural polymers and inorganic solids e.g., iron based magnetic particles on the nanometer scale. The bionanocomposites are thus combination of synthetic and biological polymers. Hence it involves coating inorganic particles with synthetic polymers to introduce surface functional groups which are subsequently used for the anchorage of biopolymers. ${ }^{2}$ The combined biohybrid materials with its inherent biocompatibility, biodegradability and high-surface area-to-volume ratio exhibit improved

${ }^{a}$ Institute on Membrane Technology ITM-CNR, National Research Council of Italy, Via P. Bucci, CUBO 17/C UNICAL Campus, 87036 Rende (CS), Italy. E-mail: abayneshy@ yahoo.com; a.gebreyohannes@itm.cnr.it; l.giorno@itm.cnr.it; r.mazzei@itm.cnr.it; t. poerio@itm.cnr.it

${ }^{b}$ Laboratoire de Génie Chimique, Université de Toulouse, CNRS, INPT, UPS, Toulouse, France. E-mail: Pierre.Aimar@univ-toulouse.fr

${ }^{c}$ Centrum voor Oppervlaktechemie en Katalyse Dept. $M^{2} S$, Faculteit Bioingenieurswetenschappen, KU Leuven, Leuven Chem \& Tech, Postbus 2461, Celestijnenlaan 200F, 3001 Leuven, Belgium. E-mail: ivo.vankelecom@biw.kuleuven. be

$\dagger$ Electronic supplementary information (ESI) available. See DOI: $10.1039 / \mathrm{c} 6 \mathrm{ra} 20455 \mathrm{~d}$ structural and functional properties of great interest for various applications. ${ }^{3}$

Bionanocomposites bearing functional biomolecules, like enzymes, take inspiration from nature to develop new hybrid biomaterials that mimic the exceptional features of natural nanocomposites. In superparamagnetic nanoparticle $\left(\mathrm{NP}^{\mathrm{SP}}\right)$ based bionanocomposites, the inorganic counterpart is mainly envisaged as a stimulus-responsive hybrid system in addition to its common supporting feature to preserve the immobilized biomolecules from denaturation., ${ }^{4,5}$

On the other hand, biocatalyst immobilized on nano-sized particles e.g., titania, carbon nanotubes with maximum surface area and activity have been applied in biocatalysis. ${ }^{6-9}$ The key drawback of such stirred tank reactors (STR) with inert carrier particles is recovery of the nano-catalyst, enzymeproduct inhibition and regeneration or disposal of spent materials. ${ }^{10}$ An alternative is to coat the biocatalyst on polymeric membranes in a biocatalytic membrane reactor (BMR) ${ }^{11}$ This creates reactive surfaces for enhanced separations while eliminating the complexity of biocatalyst recovery. However, this method mainly suffers from irreversible attachment of the biocatalyst on the membrane and loss in intrinsic permselectivity of the membrane. ${ }^{12}$ In particular, enzyme deactivation during membrane cleaning is among the current bottle-necks that limit the speed-up of BMR at industrial level. 
Therefore, the assembly of enzymes on magneto-responsive nanocomposites hosts a suitable alternative to the common methods used to immobilize enzymes directly on membranes. The immobilization of enzymes on magneto-responsive nanocomposites may result in robust hybrid materials, useful for the development of innovative stimuli-responsive BMRs able to extend the life time of both membrane and enzyme. In particular, the $\mathrm{NP}^{\mathrm{SP}}$ with immobilized enzyme can be easily attracted towards the surface of a membrane using an external magnetic field. This reversible deposition of the enzyme on the membrane facilitates the removal of the enzyme before membrane cleaning, thus avoiding enzyme denaturation due to change in the membrane microenvironment that could be imposed by membrane cleaning conditions.

The research on $\mathrm{NP}^{\mathrm{SP}}$ based stimuli-responsive BMR can be regarded as a new interdisciplinary field closely related to significant topics such as biomineralization processes, bioinspired materials, biomimetic systems and bio-separations. The upcoming development of novel bionanocomposite based enzyme immobilization introducing multi-functionality thus represents a promising research topic in the development of advanced BMRs for versatile applications such as environmental remediation.

The present work focuses on the immobilization of pectinase, used as "model enzyme" on $\mathrm{NP}^{\mathrm{SP}}$ to improve the stability of the enzymes and enhance their recovery by exploiting the properties of $\mathrm{NP}^{\mathrm{SP}}$ to be easily retrieved by application of an external magnetic field.

The presence of the $\mathrm{NP}^{\mathrm{SP}}$ on the surface of the membrane prevents direct substrate-membrane interactions, hence avoiding irreversible membrane fouling. There is also efficient in situ hydrolysis of substrate at the membrane-solution interface, thanks to the hydrolytic effect of the enzyme immobilized on the $\mathrm{NP}^{\mathrm{SP}}$. Subsequently, easy removal of the dynamic layer of the enzymatically activated $\mathrm{NP}^{\mathrm{SP}}$ and easy recovery of both nanocatalyst and membrane is achievable. Hence, the present work demonstrates that our proposed system has the unique advantage of combining excellent antifouling properties of a BMR to the possibility to detach on demand the immobilized enzyme from the membrane during cleaning.

Since the dynamic layer of $\mathrm{NP}^{\mathrm{SP}}$ is formed using a nano-sized particle, a high pressure drop and increased mass transfer resistance is theoretically expected. However, the system exhibited no filtration resistance due to presence of the $\mathrm{NP}^{\mathrm{SP}}$ dynamic layer. This is a great improvement to the direct integration of enzyme into polymeric membranes, which mostly suffers from reduced intrinsic membrane permselectivity. This phenomenon is due to the alignment of the $\mathrm{NP}^{\mathrm{SP}}$ along an external magnetic field, which is applied parallel to the surface of magneto-responsive membrane. The magneto-responsive membrane, i.e. a membrane that contains $\mathrm{NP}^{\mathrm{SP}}$ within the polymer matrix, acted as a magnetic field actuator which ensured the even distribution and dispersion of $\mathrm{NP}^{\mathrm{SP}}$ over the surface of the membrane (see inset of Fig. 1).

In this work, process performance, fouling, morphological characterization and kinetic properties biofunctionalized membranes have been investigated demonstrating the

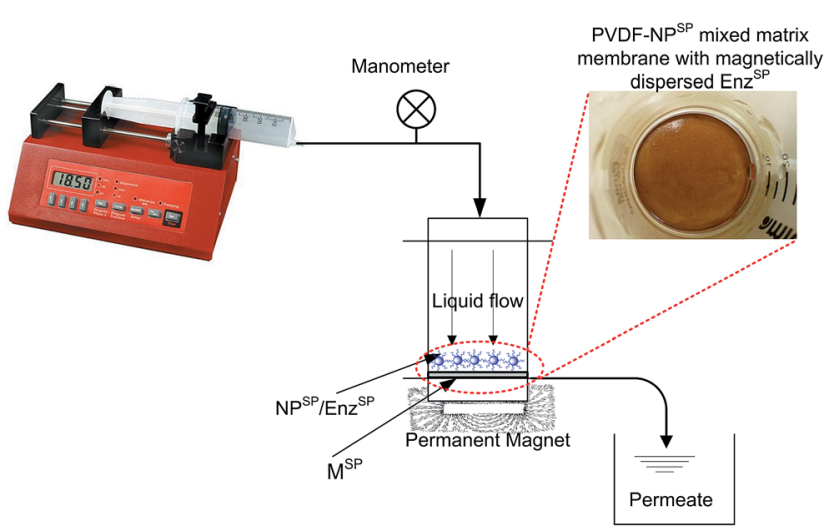

Fig. 1 Magneto-responsive microfiltration system.

upgrading of this innovative system from a basic proof-ofconcept to a validation in laboratory environment.

The performance and reproducibility of commercially available $\mathrm{NP}^{\mathrm{SP}}$ are investigated instead of using home-made $\mathrm{NP}^{\mathrm{SP}}$. Since the commercial $\mathrm{NP}^{\mathrm{SP}}$ exhibit a different particle size than what has already been used, it could also be used to overlay better understanding on the effect of particle size on the overall performance.

First, the immobilization capacity of a commercially available $\mathrm{NP}^{\mathrm{SP}}$ using enzyme pectinase is studied. Pectinase is a pectolytic enzyme capable of catalyzing the hydrolysis of glycoside bonds present in the structure of pectin, producing galacturonic acid (GalA) as its final product. Pectin are plant materials present in fruit juices, wine and vegetation wastewater. They are responsible for the formation of membrane fouling since they are gel forming agents. They thus form an impermeable layer on the membrane surface that subsequently reduces membrane performance. The activity of the enzyme was evaluated using the formation of GalA. Detailed characterization of the system through dynamic light scattering (DLS), thermo-gravimetric analysis (TGA), scanning electron microscopy (SEM) in backscattered detector (BSE) mode and wavelength-dispersive X-ray spectroscopy (WDS) is carried out. The capacity of immobilized pectinase to enhance surface biocatalysis in a continuous flow biocatalytic membrane reactor $\left(\mathrm{BMR}^{\mathrm{SP}}\right)$ is illustrated. The performance of the $\mathrm{BMR}^{\mathrm{SP}}$ is studied by varying substrate concentration, flux, and amount of $\mathrm{NP}^{\mathrm{SP}}$. Subsequently, foulant deposition on the surface of the membrane in the presence and absence of biofunctionalized $\mathrm{NP}^{\mathrm{SP}}$ was morphologically characterized.

\section{Materials and methods}

\subsection{Materials}

Citrus fruit pectin (25-35\% degree of esterification), polygalacturonase, galacturonic acid, 2-cyanoacetamide (99\%) and protein bicinchoninic acid (BCA) were obtained from SigmaAldrich (Italy); borate buffer solution ( $\mathrm{pH}$ 9.2) was from Fisher scientific. A 1\% superparamagnetic nanoparticle dispersion $\left(\mathrm{NP}^{\mathrm{SP}}\right)$, EGDE (ethylene glycol diglycidyl ether $\mathrm{MW}=174.2$ ) and 
an activation buffer were acquired from ADEMTECH (Li StarFish s.r.l., Milan, Italy).

2.1.1. Superparamagnetic nanoparticles. The $\mathrm{NP}^{\mathrm{SP}}$ used in the experiment is composed of a $1 \%$ aqueous suspension with monodispersed superparamagnetic nanoparticles. These particles have magnetic properties only when they are subjected to the action of an external magnetic field and exhibiting no residual magnetism when removed from the action of this field. They are composed of a ferric core covered by a shell of hydrophilic polymer. The polymer provides a uniform protective shell in order to isolate iron oxides which can interfere with some enzymatic reactions. They have a diameter of $200 \mathrm{~nm}, 15$ $\mathrm{m}^{2} \mathrm{~g}^{-1}$ specific surface area, and carrying positive charges in the $\mathrm{pH}$ range 2 to 10 . They contain $70 \%$ iron oxide and have a magnetic susceptibility of about $40 \mathrm{emu} \mathrm{g}^{-1}$.

The covalent immobilization of enzymes on the $\mathrm{NP}^{\mathrm{SP}}$ occurs by the functionalization of the polymer coated $\mathrm{NP}^{\mathrm{SP}}$ with carboxyl groups through which the links with the amino groups of the enzyme are established. Prior to enzyme immobilization, the $\mathrm{NP}^{\mathrm{SP}}$ was activated with EGDE (ethylene glycol diglycidyl ether MW $=174.2$ ) and an activation buffer (patented ADEMTECH, Li StarFish s.r.l., Milan, Italy) to introduce carboxylic group to the surface of the $\mathrm{NP}^{\mathrm{SP}}$. The carboxylic group eventually helped to create the covalent bond between the enzyme and the $\mathrm{NP}^{\mathrm{SP}}$.

\subsection{Activation of the $\mathrm{NP}^{\mathrm{SP}}$}

A three step procedure was followed to introduce the surface functional groups onto the polymer coated $\mathrm{NP}^{\mathrm{SP}}$. The first phase consists in treating $3 \mathrm{~mL}$ of $\mathrm{NP}^{\mathrm{SP}}(1 \%)$ with $1 \%$ activation buffer. The second stage involves the addition of $100 \mu \mathrm{L}$ EGDE per mg of $\mathrm{NP}^{\mathrm{SP}}$ followed by a thorough homogenization of the suspension. Finally the suspension was incubated for $2 \mathrm{~h}$ at 20 ${ }^{\circ} \mathrm{C}$ and maintained under constant mechanical stirring at 200 rpm. Ultimately, the $\mathrm{NP}^{\mathrm{SP}}$ activated with EGDE were washed twice with $1 \%$ activation buffer to avoid none-covalently attached EGDE.

\subsection{Enzyme immobilization}

For the immobilization of pectinase, enzyme solution was prepared by dissolving pectinase powder in a $100 \mathrm{mM}$ acetate buffer at $\mathrm{pH}$ 4.5. The mixture was left to solubilize by magnetically stirring over $24 \mathrm{~h}$.

The prepared solution containing $1.7 \mathrm{mg}$ of pectinase was put in contact with $-\mathrm{COOH}$ functionalized $\mathrm{NP}^{\mathrm{SP}}$ in duplicate and kept under mechanical stirring for $2 \mathrm{~h}$ at ambient temperature, inorder to covalently attach the enzyme to the surface of the $\mathrm{NP}^{\mathrm{SP}}$.

At the end of immobilization procedures, the enzymatically functionalized $\mathrm{NP}^{\mathrm{SP}}\left(\mathrm{Enz}^{\mathrm{SP}}\right)$ were separated from the reaction mixture by using an external permanent magnet. The magnetically isolated supernatant was kept at $4{ }^{\circ} \mathrm{C}$ for indirect quantification of the amount of immobilized enzyme, by mass balance. Subsequently, the particles were washed trice with ultrapure water. The three step wash water was spectrophotometrically analyzed at a wavelength of $280 \mathrm{~nm}$ to assess the possible presence of protein leached during the washing.

To quantify the amount of immobilized enzyme, the immobilization solution before and after immobilization was measured by the BCA assay. The amount of immobilized enzyme was then calculated as:

$$
\text { Mass }_{\text {immob. }}=\text { mass }_{\text {initial soln }}-\text { mass }_{\text {final soln }}-\text { mass }_{\text {washing soln }}
$$

Alternatively, a known amount of pectinase immobilized $\mathrm{Enz}^{\mathrm{SP}}$ was injected directly in the BCA reaction medium for quantification of the amount of enzyme immobilized on the surface of the $\mathrm{NP}^{\mathrm{SP}}$.

\subsection{Measurement of enzyme activity}

The activity of the immobilized enzyme in a STR and flowthrough MF was evaluated by measuring the rate of product formation.

During the activity measurement, the concentration of the substrate must always be in excess of the enzyme in order to saturate the enzyme completely. For enzymes that obey the Michaelis-Menten kinetics, a substrate concentration equal to ten times the $K_{\mathrm{m}}$ is sufficient to bring the reaction rate very close to the $V_{\max }$. Hence the concentration of pectin in the STR was set at $4 \mathrm{~g} \mathrm{~L}^{-1}$, i.e. about ten times more than the $K_{\mathrm{m}}$ value $(0.5 \mathrm{~g}$ $\mathrm{L}^{-1}$ ) obtained for free enzyme in our previous work. ${ }^{13}$ The solution was kept under stirring for about $30 \mathrm{~min}$ at $40{ }^{\circ} \mathrm{C}$ prior to adding the $\mathrm{Enz}^{\mathrm{SP}}$.

The method of detecting the GalA is based on the Knoevenagel condensation reaction between the active methyl group of cyanoacetamide and the aldehyde group of GalA to form a colored product..$^{14}$ Hence, at the end of the reaction time, $1 \mathrm{~mL}$ of hydrolysate withdrawn from the reaction mixture was added to $2 \mathrm{~mL}$ of cold borate buffer to instantaneously terminate the reaction. After adding $1 \mathrm{~mL}$ of $1 \%$ 2-cyanoacetamide, the vortex mixed mixture was heated to $100{ }^{\circ} \mathrm{C}$ in an oil bath for 10 minutes. The absorbance of the sample, after cooling to room temperature, was measured at a wavelength of $274 \mathrm{~nm}$ against ultrapure water. Results were normalized with background GalA concentrations that were present in the feed solution prior to the enzymatic hydrolysis. ${ }^{15}$ The concentration of GalA was calculated from the standard curve obtained using solutions of GalA at different concentrations ( 0.01 to $\left.0.3 \mathrm{~g} \mathrm{~L}^{-1}\right)$. The enzyme activity is defined as the amount of GalA produced per min $\left(\mu \mathrm{mol} \mathrm{min}^{-1}\right)$ at $40^{\circ} \mathrm{C}$ and $\mathrm{pH} 4.5$.

\subsection{Experimental set-up}

The efficacy of the Enz ${ }^{\mathrm{SP}}$ for the biocatalytic reduction of fouling was evaluated through an MF system (Fig. 1) consisting of a syringe pump (New Era Pump Systems Inc), plastic syringe with $100 \mathrm{~mL}$ capacity, a digital manometer (WIKA corporate), a metallic part-free dead-end membrane module (Amicon cell), and a permanent magnet. The filtration cell is immersed in a thermo regulated water bath in order to have better control 
over the filtration temperature. The membrane used for filtration was lab-made magnetic responsive polyvinylidene fluoride (PVDF) membrane. It is basically a mixed matrix membrane prepared by mixing a $0.33 \mathrm{w} / \mathrm{w} \%$ home-made $\mathrm{NP}^{\mathrm{SP}}$ that has an average particle size of $8 \mathrm{~nm}$. The membrane has an average pore size of $0.1 \mu \mathrm{m}$. Further details on the membrane properties are provided in our previous work. ${ }^{\mathbf{1 2}}$

The membrane was tested by the following operating conditions: from $0.01 \mathrm{~g} \mathrm{~L}^{-1}$ to $1 \mathrm{~g} \mathrm{~L}^{-1}$ of pectin concentration, from 1 to $9 \mathrm{~g} \mathrm{~m}^{-2}$ of $\mathrm{Enz}^{\mathrm{SP}}$ amount per membrane area, flux ranging from 15 to $45 \mathrm{~L} \mathrm{~m}^{-2} \mathrm{~h}^{-1}$ and filtration temperature to $40{ }^{\circ} \mathrm{C}$. The system performance was evaluated by measuring the change in transmembrane pressure (TMP) required to keep the flux constant in a continuous flow $\mathrm{BMR}^{\mathrm{SP}}$.

\subsection{Membrane and $\mathrm{NP}^{\mathrm{SP}}$ characterization}

The $\mathrm{NP}^{\mathrm{SP}}$ size and size distribution before and after enzyme immobilization was determined by dynamic light scattering (DLS) (Mastersizer 2000, Malvern Instruments) in sodium acetate buffer at pH 4.5 (a buffer suitable for enzyme pectinase) after sonicating a diluted sample to avoid particles aggregation. Thermo-gravimetric analysis (TGA) was conducted using a Perkin-Elmer TGA 6 at a constant heating rate of $5{ }^{\circ} \mathrm{C} \mathrm{min}^{-1}$ from room temperature to $500{ }^{\circ} \mathrm{C}$ in a $\mathrm{N}_{2}$ environment.

To study the topography and distribution of the magnetically deposited $\mathrm{Enz}^{\mathrm{SP}}$, cross-section of the $\mathrm{Enz}^{\mathrm{SP}}$-loaded membranes that was used under various operating conditions were observed by means of scanning electron microscopy (SEM) images, backscattered electron images (BSE) and wavelength dispersive X-ray spectroscopy (WDS) elemental maps with a high resolution SEM (FEI QUANTA 200 SEM). Membrane samples were broken in liquid nitrogen to keep the film structure unaltered. SEM analyses were also carried out, after air drying of a dispersion of $\mathrm{NP}^{\mathrm{SP}}$ on a carbon tape.

\section{Results and discussion}

\section{1. $N P^{\mathrm{SP}}$ characterization}

Fig. 2a represents SEM micrographs of the $\mathrm{NP}^{\mathrm{SP}}$, which hold a monodispersed particle size. In agreement with the information provided by the supplying company, DLS analysis (Fig. S1a $\dagger$ ) indicated an average particle size of $200 \mathrm{~nm}$ with polydispersity index (pdi) of 0.105 . As expected, Fig. 2 b shows that the $\mathrm{NP}^{\mathrm{SP}}\left(\mathrm{Enz}^{\mathrm{SP}}\right)$ exhibited a slightly higher particle size due to biofunctionalization (216-250 nm) with 0.06 pdi (Fig. S1b $\dagger$ ). Moreover, the $\mathrm{Enz}^{\mathrm{SP}}$ which were well dispersed in the liquid medium responded well to the applied magnetic field, by getting preferentially attached to the point of high magnetic field gradient (see inset of Fig. $\mathrm{S} 2 \dagger$ ).

TGA curves show single transitions for both native and EDGE modified $\mathrm{NP}^{\mathrm{SP}}$ samples between $200{ }^{\circ} \mathrm{C}$ and $350{ }^{\circ} \mathrm{C}$ (Fig. 2c). This desorption is explained by the decomposition of the
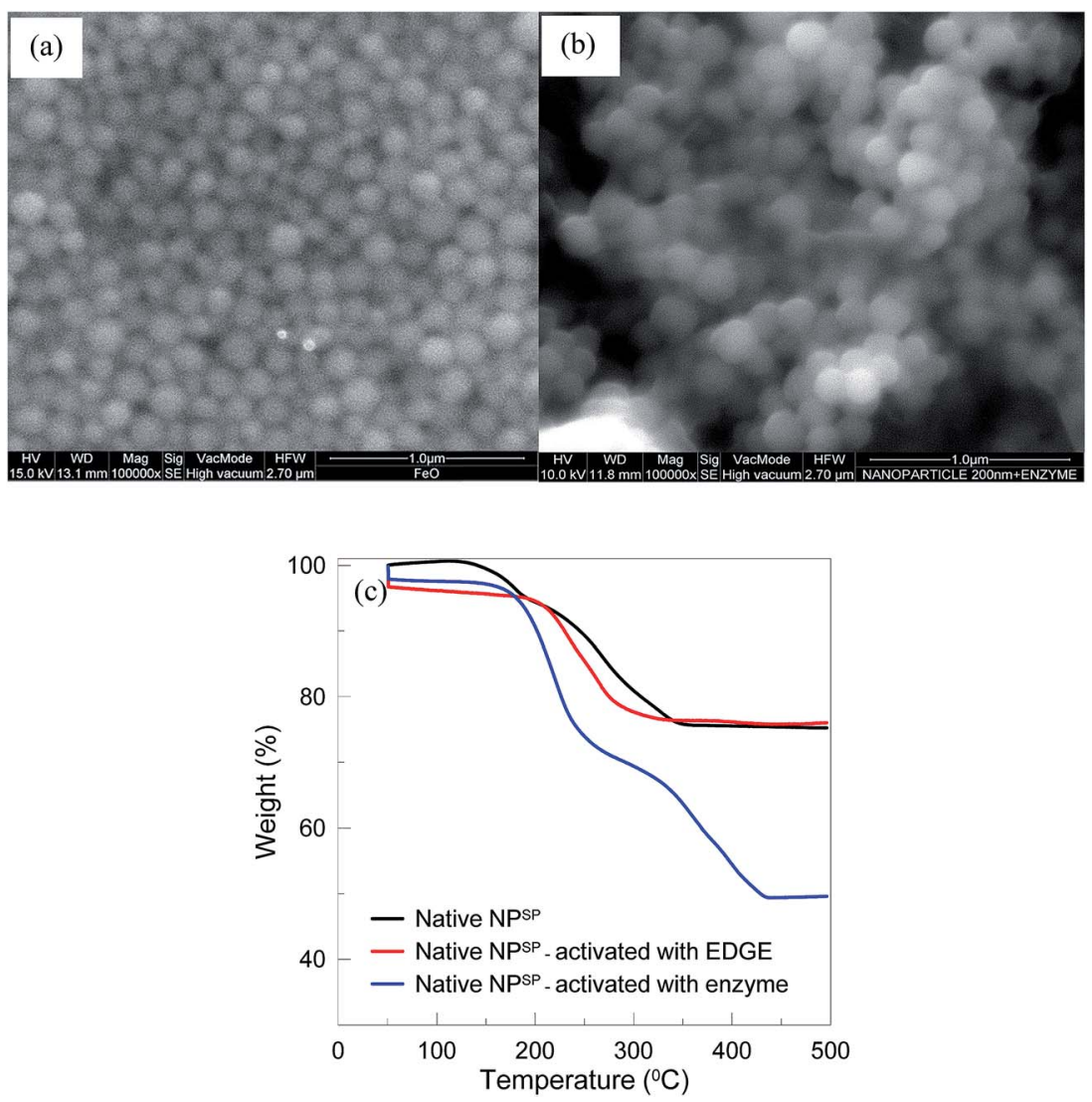

Fig. 2 Characterization of NPS before and after enzyme immobilization (a) SEM of NPP before immobilization; (b) SEM of NP ${ }^{S P}$ after pectinase immobilization; (c) TGA profile of NPS. 
polymer shell used to coat the $\mathrm{NP}^{\mathrm{SP}}$. For the $\mathrm{Enz}^{\mathrm{SP}}$ however, there were two-step desorption processes that occurred in the vicinity of $200{ }^{\circ} \mathrm{C}$ and $300{ }^{\circ} \mathrm{C}$ and $300{ }^{\circ} \mathrm{C}$ to $450{ }^{\circ} \mathrm{C}$. The two step desorption processes were explained by the quasi-two-layers adsorbed models on the particle surface. ${ }^{16}$ The first one, which corresponds to a $30 \%$ weight loss, was due to the decomposition of the immobilized enzyme, while the second one, which corresponds to a $20 \%$ weight loss, was due to the polymer coating layer.

\subsection{Magnetic dispersion of $\mathrm{Enz}^{\mathrm{SP}}$ the on membrane surface}

Surface and cross-sectional WDS maps of the membrane layered with $3 \mathrm{~g} \mathrm{~m}^{-2} \mathrm{Enz}^{\mathrm{SP}}$ are shown in Fig. 3. Fig. 3a shows SEM images of the cross-section view of the membrane that contained $3 \mathrm{~g} \mathrm{~m}^{-2} \mathrm{Enz}^{\mathrm{SP}}$ prior to the WDS elemental mapping. The images of the chemical elemental maps, acquired by WDS, show the spatial distribution of elements in the analyzed samples. The different concentrations of each element are shown by the color coding. By this mapping, it is possible to observe the uniform dispersion of the $\mathrm{Enz}^{\mathrm{SP}}$ over the surface of the membrane. High intensities, as represented by reddish/ pinkish color (Fig. 3b), confirm the presence of Fe-rich dynamic layer. The area that shows green patches was most likely due to peeling-off the dynamic layer during sample drying and preparation for WDS.

Fig. $3 \mathrm{c}$ is the single element map of Fe along the membrane cross-section containing $3 \mathrm{~g} \mathrm{~m}^{-2} \mathrm{Enz}^{\mathrm{SP}}$ after filtering $0.3 \mathrm{~g} \mathrm{~L}^{-1}$ pectin solution at $15 \mathrm{~L} \mathrm{~m}^{-2} \mathrm{~h}^{-1}$. The higher concentration of the $\mathrm{Enz}^{\mathrm{SP}}$ on the top surface can be clearly recognized by its reddish/yellowish color in the map. The mixture of various colors shown in the map is attributed to the presence of raw or partially hydrolyzed pectin that could interfere with the detection of Fe. The membrane cross-section below the dynamic layer revealed a blue color related to low Fe concentration in the shown color coding.

\subsection{Application of pectinase functionalized $\mathrm{NP}^{\mathrm{SP}}$ in a membrane bioreactor}

The $\mathrm{Enz}^{\mathrm{SP}}$ was used in a $\mathrm{BMR}^{\mathrm{SP}}$ for the hydrolysis of pectin contained in different streams. The effect of membrane fouling due to adsorbed pectin in the $\mathrm{BMR}^{\mathrm{SP}}$ was evaluated by measuring the change in TMP required to keep the flux constant in a constant volume and constant flow MF.

As shown in Fig. 4, two systems, one containing a $3 \mathrm{~g} \mathrm{~m}^{-2}$ dynamic layer of neutral $\mathrm{NP}^{\mathrm{SP}}$ and another containing a $3 \mathrm{~g} \mathrm{~m}^{-2}$ immobilized pectinase containing $\mathrm{Enz}^{\mathrm{SP}}$, were run in parallel. In both cases, the dynamic layer could prevent direct membrane-foulant interaction, hence avoiding a possible future membrane replacement due to irreversible fouling formation. When the $\mathrm{Enz}^{\mathrm{SP}}$ was used, the system faced limited effect of fouling thanks to the hydrolytic action exerted by the $\mathrm{Enz}^{\mathrm{SP}}$ on the adsorbed pectin.

In Fig. 5 SEM micrographs of membranes characterized after the filtration of $0.3 \mathrm{~g} \mathrm{~L}^{-1}$ of pectin solution using a constant flux of $15 \mathrm{~L} \mathrm{~m}^{-2} \mathrm{~h}^{-1}$ is shown. The first column (Fig. 5(1a and b)) represents the magnetic responsive bare membrane after pectin filtration. The membrane was fully covered with the foulant while the cross-sectional image revealed a $3 \mu \mathrm{m}$ thick foulant layer. In the second column (Fig. 5(2a and b)), before the fouling experiment, a dynamic layer $3 \mathrm{~g} \mathrm{~m}^{-2}$ neutral $\mathrm{NP}^{\mathrm{SP}}$ was
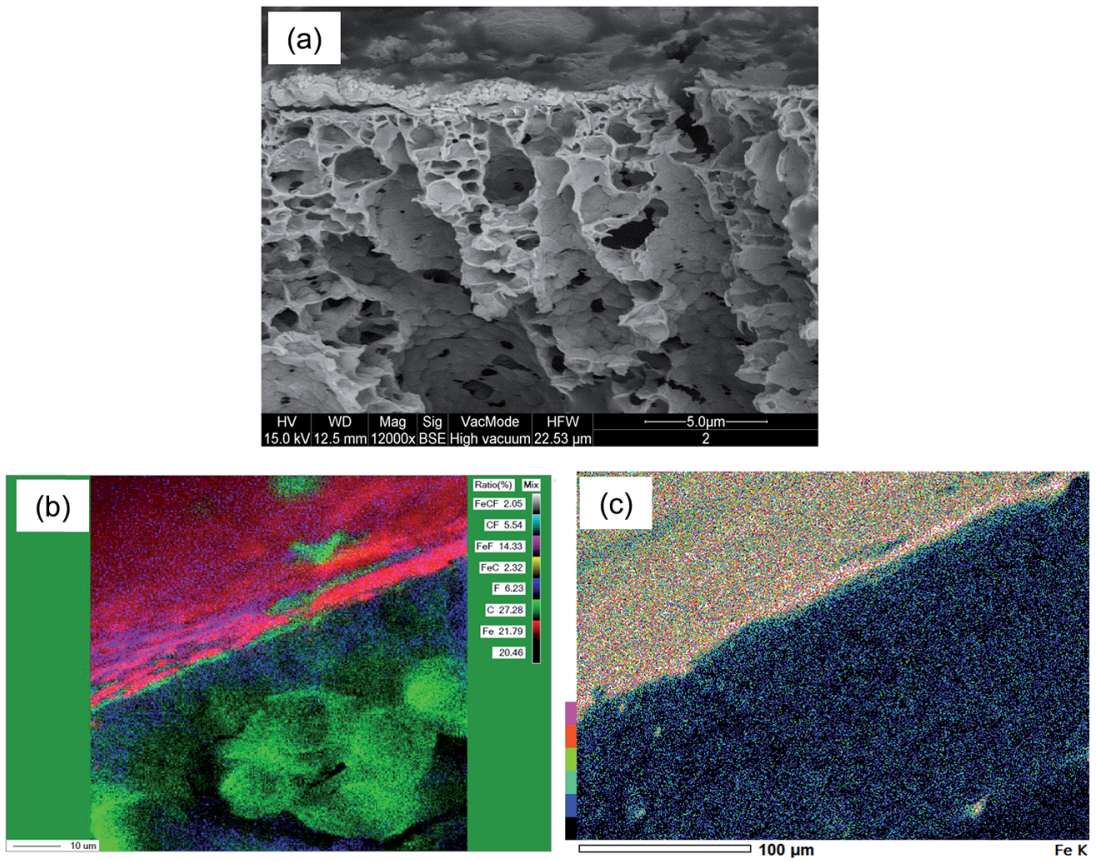

Fig. 3 WDS mapping of a membrane with a $3 \mathrm{~g} \mathrm{~m}^{-2} \mathrm{Enz}^{\mathrm{SP}}$ dynamic layer (a) SEM of membrane with Enz ${ }^{\mathrm{SP}}$ before WDS; (b) WDS of membrane with $\mathrm{Enz}^{\mathrm{SP}}$ layer showing distribution of the various elements found on the membrane (Enz ${ }^{\mathrm{SP}}$ ) along the membrane cross-section and; (c) WDS map showing the elemental distribution of Fe along the membrane cross-section. 


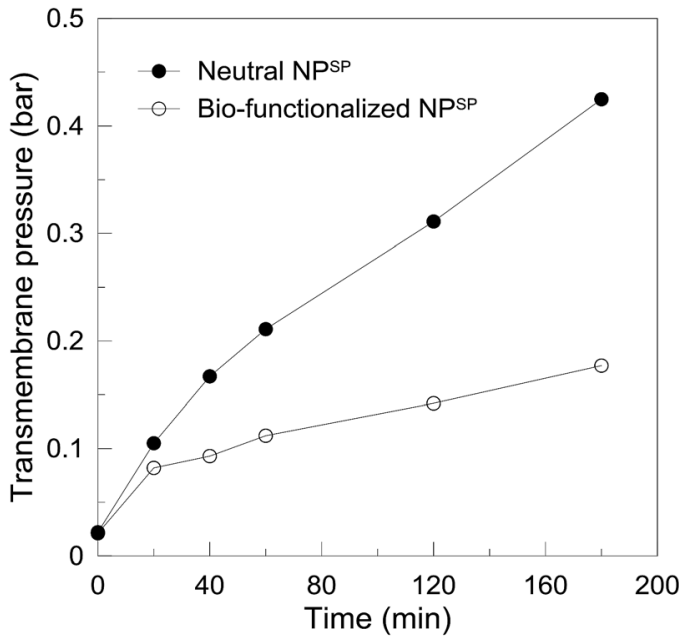

Fig. 4 Transmembrane pressure as a function of time obtained using $3 \mathrm{~g} \mathrm{~m}^{-2}$ neutral NP $\mathrm{SP}^{\mathrm{SP}} 3 \mathrm{~g} \mathrm{~m}^{-2} \mathrm{Enz}^{\mathrm{SP}}$ at $15 \mathrm{~L} \mathrm{~m}^{-2} \mathrm{~h}^{-1}$ constant flux, $0.3 \mathrm{~g} \mathrm{~L}^{-1}$ pectin solution and $40^{\circ} \mathrm{C}$ in a continuous flow MF.

magnetically attracted to the membrane surface while the third one contained similar amount of $\mathrm{Enz}^{\mathrm{SP}}$. It is worth noting that due to the in situ degradation of the pectin by the immobilized pectinase, the thickness of the $\mathrm{Enz}^{\mathrm{SP}}$ (Fig. 5(3a and b)) plus the foulant layer were $30 \%$ and $67 \%$ lower than the total thickness observed for membranes containing neutral $\mathrm{NP}^{\mathrm{SP}}$ layer or no particles at all respectively.

3.3.1. Effect of feed concentration. Fig. 6a represents the TMP when pectin concentration was step-wise increased from $0.01 \mathrm{~g} \mathrm{~L}^{-1}$ to $1 \mathrm{~g} \mathrm{~L}^{-1}$. For all feed concentrations, the initial TMP rise was sharp. However, at the low feed concentration, the TMP levels off immediately after the onset of filtration. This is attributed to the lower amount of substrate available which either well balanced the reaction rate with the mass transfer rate or which limited the mass transfer rate and subsequent sub-saturation of the enzyme with substrate. On the contrary at increased feed concentration, the TMP rised faster, possibly causing oversaturation of the enzyme with substrate. In Fig. 6b, the rate of fouling for each feed concentration, defined as the change in TMP per unit time is exhibited. At lower feed concentrations, there is a visible lag-phase in the rate of fouling. However, the rate revealed an exponential increase at higher feed concentration, possibly due to $\mathrm{Enz}^{\mathrm{SP}}$ oversaturation with substrate.

In Fig. 7, surface and cross-sectional SEM micrographs of the membranes used in the different feed concentrations are depicted. Similar to the TMP trend observed in Fig. 6, the total thickness of (foulant $+\mathrm{Enz}^{\mathrm{SP}}$ ) layer increased with increased substrate concentration. Nevertheless, thanks to the hydrolytic effect of the $\mathrm{Enz}^{\mathrm{SP}}$, when the feed concentration was raised tenfold, there only was a fivefold increase (from $1 \mu \mathrm{m}$ to $5 \mu \mathrm{m}$ ) in the thickness of the layer. From the SEM surface images, a significantly different morphological structure of the foulant layer under different feed concentration can also be observed. In particular, the membrane used with the $1 \mathrm{~g} \mathrm{~L}^{-1}$ feed revealed the formation of bigger aggregates of foulants. These aggregates might be the result of a thick layer of foulant formed on the surface of the biocatalytic layer that eventually induced bigger aggregate formation upon drying the sample in the process of making it ready for the SEM analysis.

Moreover, all SEM micrographs are taken in backscattered detection (BSE) mode. BSE images display atomic number contrast with brighter regions being generated from areas of higher average atomic number. The surface micrographs showed a very bright image when low feed concentration $(0.1 \mathrm{~g}$ $\mathrm{L}^{-1}$ ) was used. This is due to better visibility of iron contained in the $\mathrm{Enz}^{\mathrm{SP}}$ layer as there was only a very thin layer of foulants.
(1)

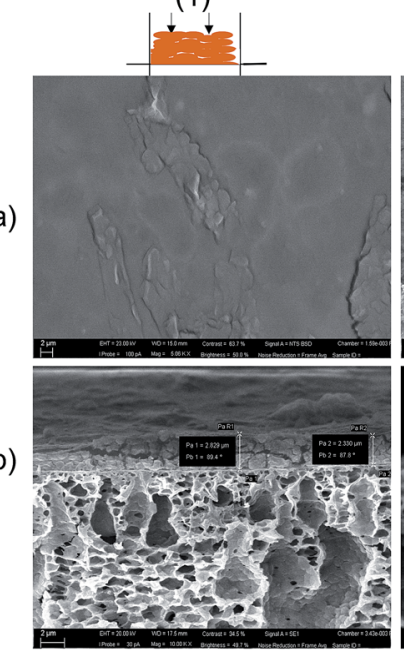

bare membrane:

2.3- $2.8 \mu \mathrm{m}$
(2)

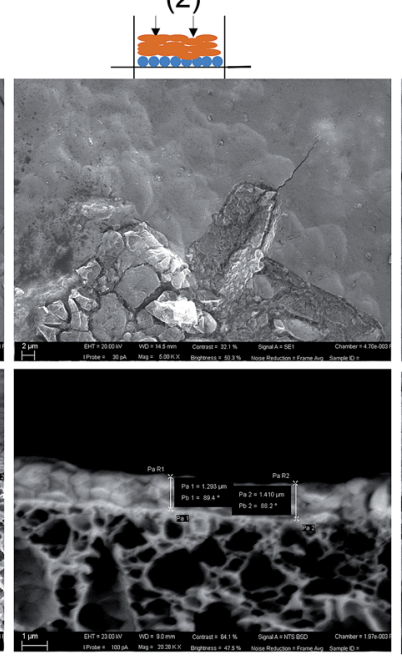

NPSP: 1.3- $1.4 \mu \mathrm{m}$
(3)

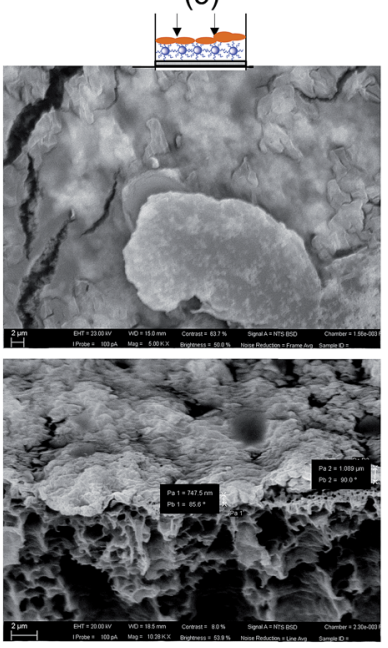

Enz ${ }^{\text {SP: }} 0.7-1 \mu \mathrm{m}$

Fig. 5 Surface (a) and cross-sectional (b) SEM micrographs of membrane after filtration with $0.3 \mathrm{~g} \mathrm{~L}^{-1}$ pectin at $15 \mathrm{~L} \mathrm{~m}^{-2} \mathrm{~h}^{-1}$ under different conditions: (1) without NPSP , (2) with NPP 

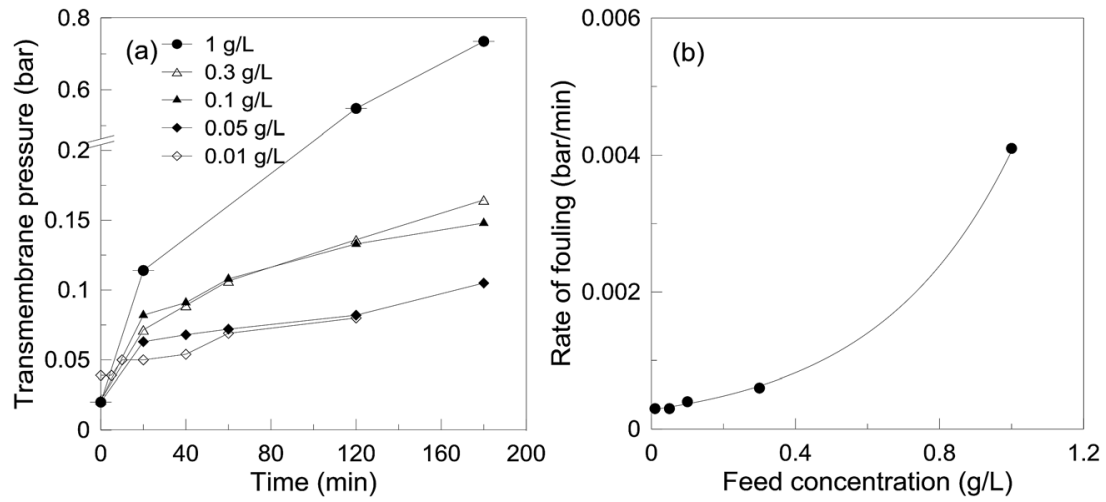

Fig. 6 Effect of feed concentration on the filtration performance at $15 \mathrm{~L} \mathrm{~m}^{-2} \mathrm{~h}^{-1}$ constant flux, $3 \mathrm{~g} \mathrm{~m}^{-2} \mathrm{Enz}^{\mathrm{SP}}$ and $40{ }^{\circ} \mathrm{C}$; (a) TMP trend and (b) rate of fouling.

However, with increased feed concentration and the subsequent thick layer of foulant, the bright color started to fade. These color patterns were also in good agreement with the observed TMP trend.

3.3.2. Evaluation of kinetic performance. In addition to filtration, the kinetic performance of the reactive filtration was evaluated according to eqn (7) (see ESI $\dagger$ ). Attributed to the stable covalent bonding, the concentration of GalA produced at each feed concentration and fixed flux of $15 \mathrm{~L} \mathrm{~m}^{-2} \mathrm{~h}^{-1}$ and with $\mathrm{Enz}^{\mathrm{SP}}$ containing $0.2 \mathrm{mg}$ enzyme was constant over time (Fig. 8a). The volumetric reaction rate $\left(v_{\mathrm{r}}\right)$ increased linearly when the feed concentration was increased from 0.01 to $0.3 \mathrm{~g}$ $\mathrm{L}^{-1}$. Based on the Lineweaver-Burk plot (Fig. 8b), the maximum reaction rate $\left(V_{\max }\right)$ and the Michaelis constant $\left(K_{\mathrm{m}}\right)$ were 0.015 $\left(\mathrm{M} \mathrm{h}^{-1}\right)$ and $0.44\left(\mathrm{~g} \mathrm{~L}^{-1}\right)$ respectively. The $K_{\mathrm{m}}$ value obtained here is in the same range as the $K_{\mathrm{m}}$ value of a free enzyme in an STR $\left(0.5 \mathrm{~g} \mathrm{~L}^{-1}\right) .{ }^{13}$ Hence, immobilization of the enzyme on the $\mathrm{NP}^{\mathrm{SP}}$ did not affect the substrate affinity for the enzyme.
3.3.3. Effect of amount of $\mathrm{Enz}^{\mathrm{SP}}$ deposited per membrane area. A very interesting aspect of BMR is the possibility to increase the system efficiency by increasing the amount of enzyme loaded on the membrane. However, with the conventional methods of enzyme immobilization, the enzyme loading capacity of the membrane is limited by several factors. For instance, the amount of enzyme that can be covalently attached directly on the surface of a membrane is limited by the available surface area for immobilization. Formation of multi-layers of enzyme results in cross-linking of the enzyme, causing molecular crowding. ${ }^{17}$ This molecular crowding produces highly nonlinear effects on the effective concentration of macromolecules. First, crowding will reduce the diffusion rates of both large and small molecules, causing reduction in reaction rate. In addition, crowding reduces the amount of biocatalytic sites that should be actively engaged in the biocatalysis.

In the current system, in order to increase the amount of enzyme on the surface of the membrane, the amount of Enz ${ }^{\text {SP }}$

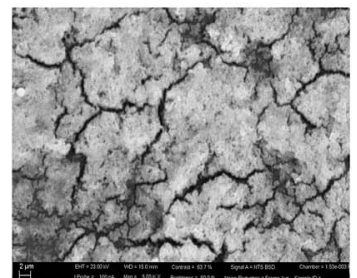

$0.1 \mathrm{~g} / \mathrm{L}$ pectin- $0.2 \mathrm{mg} \mathrm{Enz-}$ $15 \mathrm{LMH}$

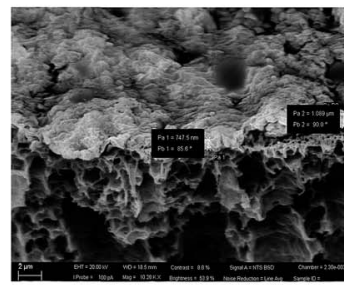

$0.1 \mathrm{~g} / \mathrm{L}$ pectin- $0.2 \mathrm{mg}$ Enz- 15 LMH: $0.7-1 \mu \mathrm{m}$

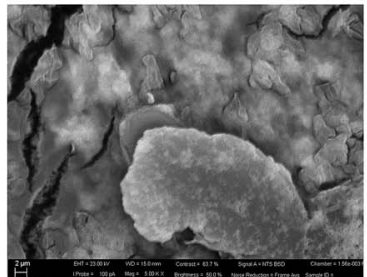

$0.3 \mathrm{~g} / \mathrm{L}$ pectin- $0.2 \mathrm{mg}$ Enz$15 \mathrm{LMH}$

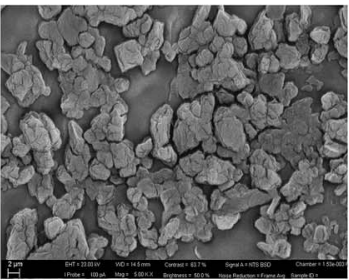

$1 \mathrm{~g} / \mathrm{L}$ pectin- $0.2 \mathrm{mg}$ Enz$15 \mathrm{LMH}$

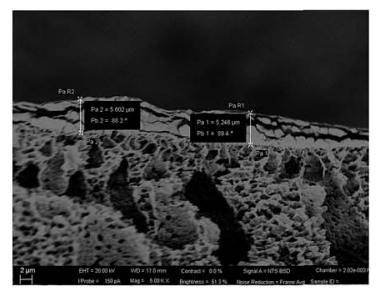

$1 \mathrm{~g} / \mathrm{L}$ pectin- $0.2 \mathrm{mg}$ Enz-15 LMH: $5.0-5.3 \mu \mathrm{m}$

Fig. 7 Effect of feed concentration on the formation of the fouling layer on the membrane. 

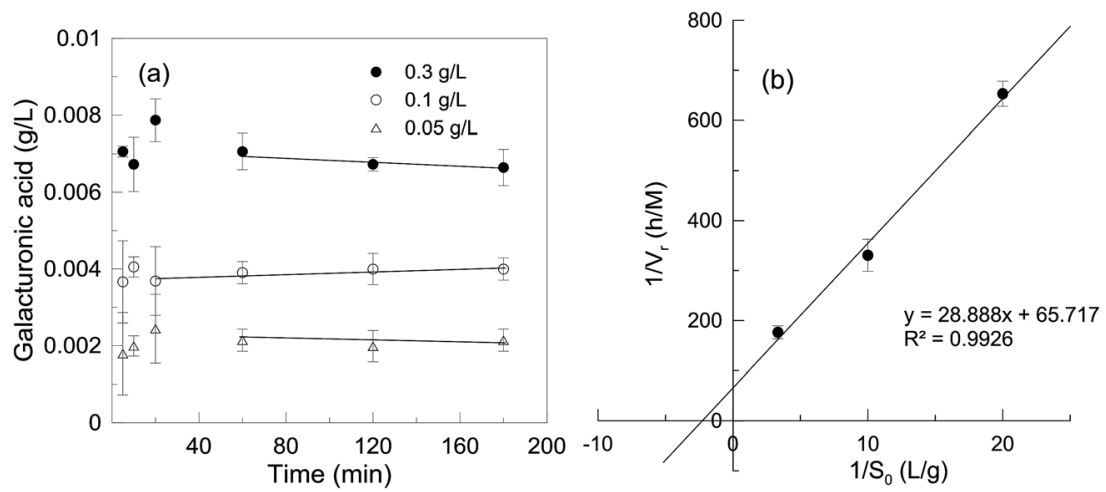

Fig. 8 Kinetic performance of the BMR ${ }^{\mathrm{SP}}$ at $15 \mathrm{~L} \mathrm{~m}^{-2} \mathrm{~h}^{-1}$ constant flux, $3 \mathrm{~g} \mathrm{~m}^{-2} \mathrm{Enz}^{\mathrm{SP}}$ and $40^{\circ} \mathrm{C}$; (a) GalA concentration and (b) Lineweaver-Burk plot. The concentration GalA at inlet is zero, so the line in figure a represent the concentration at the outlet.

was increased. By increasing the amount of $\mathrm{Enz}^{\mathrm{SP}}$, it was possible to pack a multilayer of enzyme with a better distribution i.e. increase the surface area for enzyme immobilization over a given membrane area. As a result, the TMP required to keep the flux constant at $15 \mathrm{~L} \mathrm{~m}^{-2} \mathrm{~h}^{-1}$ decreased significantly while increasing the amount of $\mathrm{Enz}^{\mathrm{SP}}$ deposited per membrane area (Fig. 9a). The rate of fouling indicated in Fig. 9b also showed a logarithmic reduction. Hence, it resolved the issue of limited surface area for enzyme immobilization.

Looking at the SEM images in Fig. 10, a threefold increase in the amount of $\mathrm{Enz}^{\mathrm{SP}}$, resulted in a twofold reduction of the total thickness. Since the amount of $\mathrm{Enz}^{\mathrm{SP}}$ at the lowest enzyme concentration is significantly low, the relatively thicker layer of deposits observed at the lowest $\mathrm{Enz}^{\mathrm{SP}}$ was mainly due to membrane foulants.

3.3.4. Effect of flux. In addition to feed and enzyme concentration, transmembrane flux is a crucial parameter that determines the system efficiency by governing mass transfer. When mass transfer rate prevails reaction rate under nonstirred conditions, a continuous build-up of foulants and subsequent increase in TMP is required. In Fig. 11a, at fluxes of 30 and $45 \mathrm{~L} \mathrm{~m}^{-2} \mathrm{~h}^{-1}$, the TMP rises almost linearly. Yet, the TMP at $15 \mathrm{~L} \mathrm{~m}^{-2} \mathrm{~h}^{-1}$ was well below 0.5 bar while achieving a quasi-steady state value over the entire duration (Fig. 11a). Furthermore, the rate of fouling for both neutral and $\mathrm{BMR}^{\mathrm{SP}}$ increased linearly with increased flux (Fig. 11b). However, the curve for the $\mathrm{BMR}^{\mathrm{SP}}$ system lay well below that of the neutral system. Moreover, possibly attributed to increased $\mathrm{BMR}^{\mathrm{SP}}$ productivity at high mass transfer rate, the difference was most visible at higher flux. Hence, the $\mathrm{BMR}^{\mathrm{SP}}$ showed a better performance compared to the neutral system, even in the presence of significantly higher mass transfer rates. Moreover, for the given enzyme concentration, it is clear that $15 \mathrm{~L} \mathrm{~m}^{-2} \mathrm{~h}^{-1}$ was an optimum.

In agreement with the TMP trend, when the flux was increased from 15 to $45 \mathrm{~L} \mathrm{~m}^{-2} \mathrm{~h}^{-1}$, where mass transfer rate prevails reaction rate, the thickness of the deposit on the membrane increased from $1 \mu \mathrm{m}$ (Fig. 11c; left) to $3 \mu \mathrm{m}$ (Fig. 11d; right).

\subsection{Performance comparison between lab-made and commercial $\mathrm{NP}^{\mathrm{SP}}$}

The performance and reproducibility of commercially available $\mathrm{NP}^{\mathrm{SP}}$ are compared with our previously used home-made $\mathrm{NP}^{\mathrm{SP}}$ with the aim to upgrade this innovative system from a basic proof-of-concept to a validation in laboratory environment.

Owing to the high surface-area-to-volume ratio, the $8 \mathrm{~nm} \mathrm{NP}^{\mathrm{SP}}$ are more biologically active than the $200 \mathrm{~nm} \mathrm{NP}^{\mathrm{SP}}$. The $8 \mathrm{~nm} \mathrm{NP}^{\mathrm{SP}}$ thus exhibited a six-fold higher pectinase loading capacity $(240$ $\mathrm{mg} \mathrm{g}^{-1}$ ) compared to the $40 \mathrm{mg} \mathrm{g}^{-1}$ exhibited by $200 \mathrm{~nm} \mathrm{NP}^{\mathrm{SP}}$. As
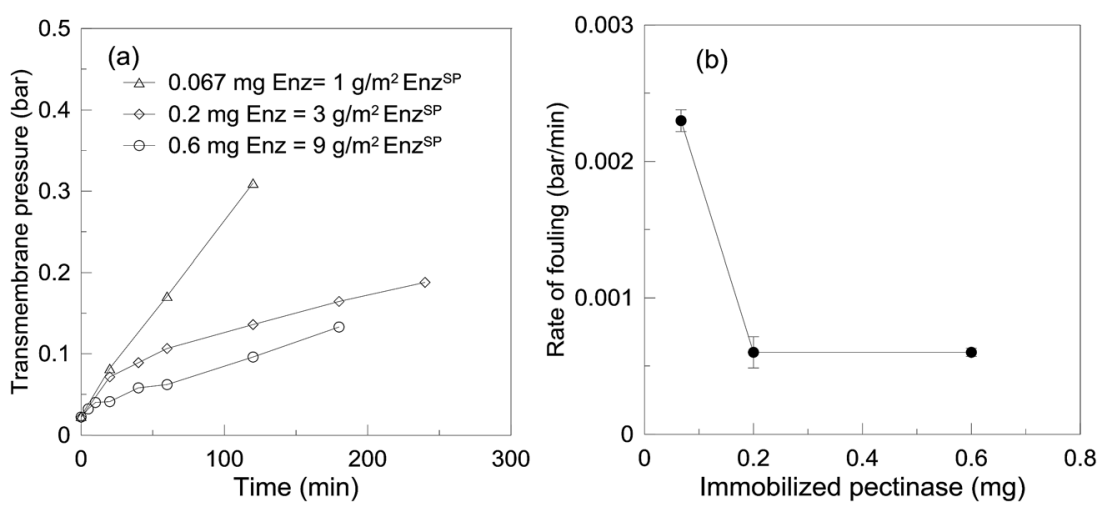

Fig. 9 TMP as a function of time (a) and rate of fouling (b) obtained using different amount of pectinase loaded NPSP. 

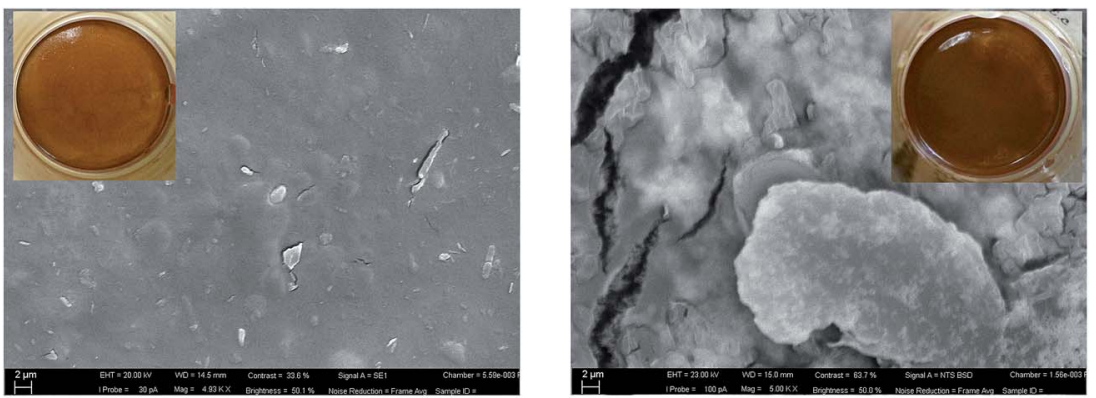

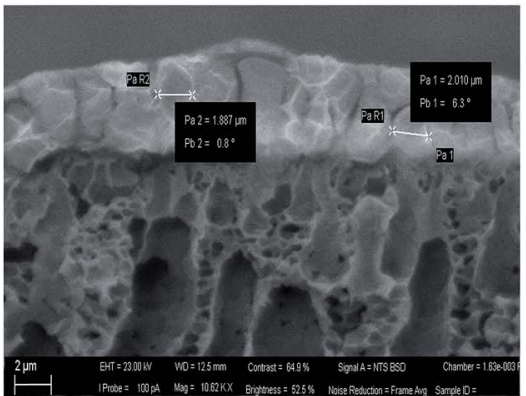

0.06 mg Enz- 15 LMH: $1.9-2 \mu \mathrm{m}$

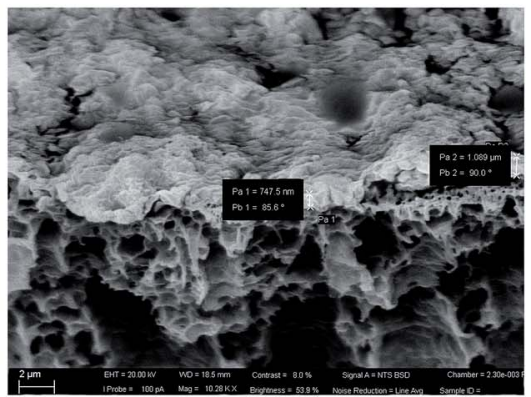

$0.2 \mathrm{mg}$ Enz- $15 \mathrm{LMH}: 0.7-1 \mu \mathrm{m}$

Fig. 10 Effect of increased amount of pectinase loaded $N P^{S P}\left(E n z{ }^{S P}\right)$ on the system.

a result, there was a significant difference in the rate of fouling defined at various flux (Fig. 12a) and feed concentration (Fig. 12b). At the lower range, they both exhibited similar performance. This could be attributed to the presence of high amounts of immobilized enzyme in both systems that can satisfy the hydrolysis of foulants transported at lower flux or feed concentration. However, with increased flux or feed concentration, while the system with high enzyme loading continued to provide limited rate of fouling, the system with low enzyme loading revealed an almost exponentially rising rate of fouling.

On the other hand, when the $200 \mathrm{~nm} \mathrm{NP}{ }^{\mathrm{SP}}$ was used, an external magnetic field was applied only to assist with the
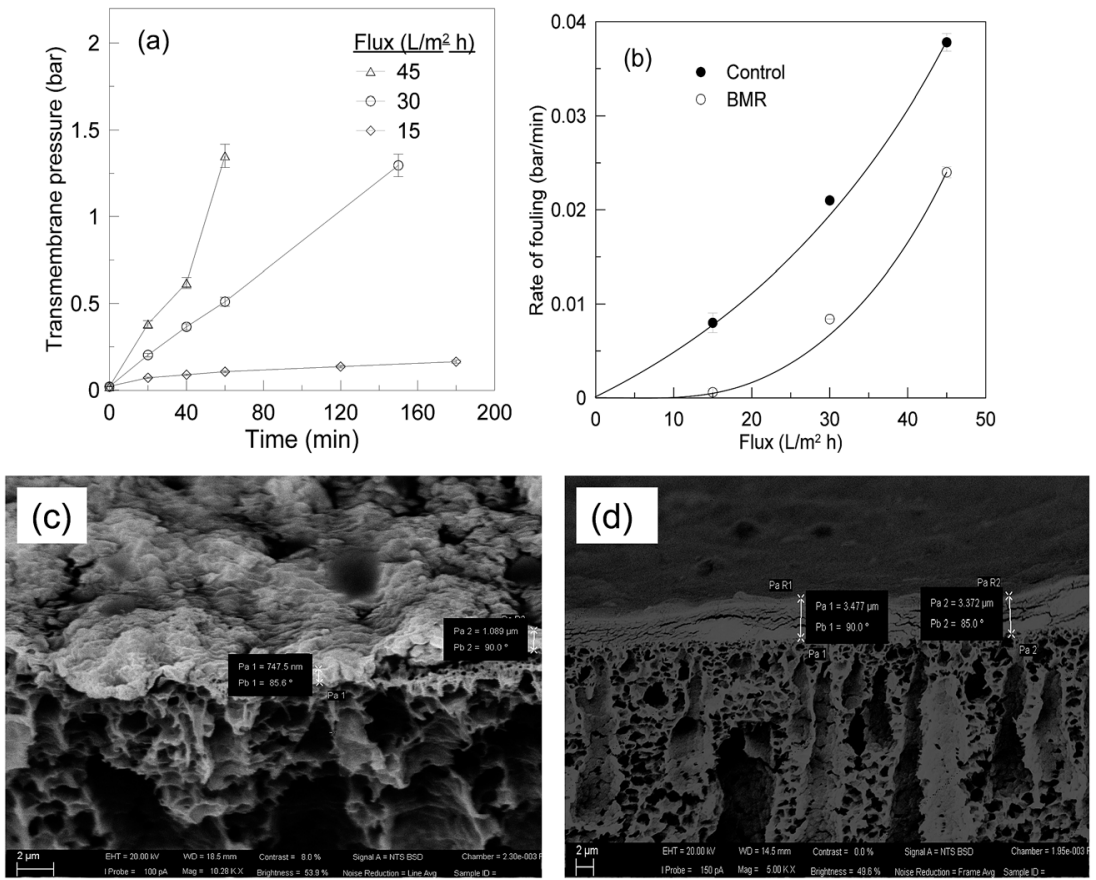

Fig. 11 Effect of transmembrane flux on $\mathrm{BMR}^{\mathrm{SP}}$ efficiency at $0.3 \mathrm{~g} \mathrm{~L}^{-1}$ pectin concentration, $3 \mathrm{~g} \mathrm{~m}^{-2} \mathrm{Enz}^{\mathrm{SP}}$ and $40{ }^{\circ} \mathrm{C}$ : (a) TMP, (b) rate of fouling at different flux for control and BMR $R^{S P}$, (c) SEM micrographs of Enz ${ }^{S P}$ layer after pectin filtration at $15 \mathrm{~L} \mathrm{~m}^{-2} \mathrm{~h}^{-1}$ and (d) SEM micrograph of Enz layer after pectin filtration at $45 \mathrm{~L} \mathrm{~m}^{-2} \mathrm{~h}^{-1}$. 

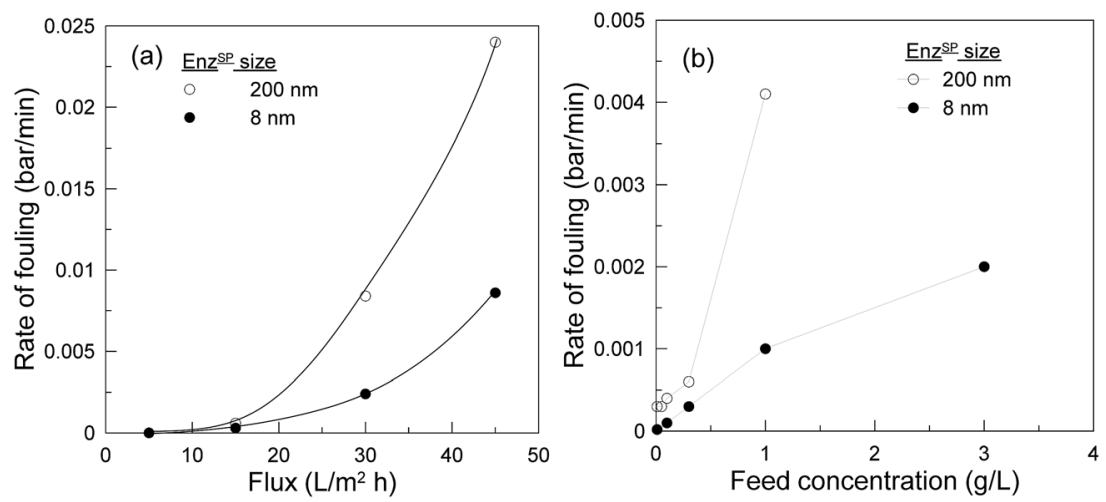

Fig. 12 Effect of particle size on the rate of fouling defined as change in TMP per unit time for BMR ${ }^{\mathrm{SP}}$ operated using an $8 \mathrm{~nm}$ home-made Enz ${ }^{\mathrm{SP}}$ and a $200 \mathrm{~nm}$ commercial Enz ${ }^{\mathrm{SP}}$ at $40{ }^{\circ} \mathrm{C} ; 0.3 \mathrm{~g} \mathrm{~L}^{-1}$ feed concentration and $3 \mathrm{~g} \mathrm{~m}^{-2} \mathrm{Enz}^{\mathrm{SP}}$ amount (a) at different flux and (b) at different feed concentration.

attraction of the $\mathrm{NP}^{\mathrm{SP}}$ towards the surface of the membrane and easy dispersion on the surface of the membrane. Once the particles were uniformly dispersed on the membrane, the particles were retained based on size exclusion. Hence, it avoided the need for constant application of an external magnetic field throughout the operation. On the contrary, for the $8 \mathrm{~nm}$ particles applying the external magnetic field constantly was highly imperative as retention on the membrane is based on magnetic interaction between the $\mathrm{NP}^{\mathrm{SP}}$ and magneto-responsive membrane. In Fig. 9b, the system efficiency was effectively enhanced by increasing the amount of $\mathrm{Enz}^{\mathrm{SP}}$ per membrane area without a significant molecular crowding. Hence, one can benefit from the easy retainability and commercial availability of the present $\mathrm{NP}^{\mathrm{SP}}$, while boosting the system efficiency to the required level through the possible high enzyme loading.

Yet, both systems exhibited similar trends when operating parameters were varied, i.e. the $\mathrm{BMR}^{\mathrm{SP}}$ exhibited good reproducibility with a commercial $\mathrm{NP}^{\mathrm{SP}}$. Scaling-up and commercialization of the developed $\mathrm{BMR}^{\mathrm{SP}}$ can thus be smooth since it avoids the complex technical and practical challenges for standardization and mass production of $\mathrm{NP}^{\mathrm{SP}}$.

In previous literature, a number of bioinspired engineered nanobeads, such as hybrid silver-silica nano-composites, ${ }^{18}$ pure silica beads, ${ }^{19}$ and graphene-bismuth nanocomposites ${ }^{20}$ have been used to immobilize enzymes in order to prevent leaching and enzyme loss during recycling. Yet, the number of available information regarding the use of these nanobeads as antifoulants in membrane operation is very limited. Even for those reported in literature, there is very limited evidence on how to easily separate neutral nanobeads from the rest of other retained components, which holds similar particles size. Most of the nanobeads used so far are being separated based on size exclusion. For instance, in the work of Zanoni et al., ${ }^{21}$ a $500 \mathrm{~nm}$ Si-nanobeads with immobilized enzyme that was used to distract biofilm growth were recovered using $0.45 \mu \mathrm{m}$ filters. However, due to the presence of residual gels that could not be isolated from the Si-nanobeads using a mere filtration, the recycled Si-nanobeads exhibited reduced mechanical or enzymatic activity on the biofilms. As a result, authors suggested the need to develop an alternative and highly efficient recovery and cleaning methodology. ${ }^{21}$ In this work, these challenges are resolved by using magneto-responsive nanobeads.

\section{Conclusions}

The use of bionanocomposites as enzyme carrier to keep membrane surfaces clean, not only protects the membrane from damage and increases its working life, but can also be considered a more environmentally friendly solution because it reduces the use of harsh membrane cleaning agents. The present work focused on the study of enzyme immobilization, specifically pectinase on $200 \mathrm{~nm}$ commercial $\mathrm{NP}^{\mathrm{SP}}$.

The enzyme was immobilized by covalent bond on functionalized $\mathrm{NP}^{\mathrm{SP}}$ using EGDE. WDS elemental mapping revealed that application of an external magnetic field helped with the formation of a thin layer of uniformly dispersed $\mathrm{Enz}^{\mathrm{SP}}$ on the surface of the membrane. The $\mathrm{Enz}^{\mathrm{SP}}$ was effective in reducing fouling during $\mathrm{MF}$ of pectin-rich solution. Characterization of the Enz ${ }^{\mathrm{SP}}$ containing membrane through SEM micrographs well agreed with the hydrodynamic behavior.

It is clear that $\mathrm{BMR}^{\mathrm{SP}}$ is a useful tool to resolve the various issues related to the current practice of enzyme immobilization techniques e.g., direct integration in the membrane matrix or use of inert carrier particles. The work demonstrated the feasibility of this innovative system in a laboratory environment and provided knowledge useful for other applications other than the used model system. Since any type of enzyme can be easily immobilized on the $\mathrm{NP}^{\mathrm{SP}}$, the system is well-suited for biotransformation that involve immobilized enzymes.

Therefore, considering the high reproducibility of the system with commercial $\mathrm{NP}^{\mathrm{SP}}$ and the modularity of membrane system, retrofitting the $\mathrm{BMR}^{\mathrm{SP}}$ in an existing process or scaling-up the new system would be relatively easy. The knowledge gained here using this commercial $\mathrm{NP}^{\mathrm{SP}}$ will then help to avoid the significant effort and investment required in the processes of standardizing the $\mathrm{NP}^{\mathrm{SP}}$ mass production while benefiting from better possibilities to select commercially available different particle sized $\mathrm{NP}^{\mathrm{SP}}$ for target biocatalysis. 


\section{Acknowledgements}

The authors acknowledge the European Union, FESR, MIUR, MSE for the financial support to the project PON Olio Più PON01_01545, within the framework PON Ricerca e Competitività 2007-2013. We are also grateful to KU Leuven for support in the frame of IDO 06/008 and OT (11/061), and the Flemish Government for the Methusalem and FWO funding (G.0808.10N) and the Federal Government for an IAP grant.

\section{References}

1 M. Darder, P. Aranda and E. Ruiz-Hitzky, Adv. Mater., 2007, 19, 1309-1319.

2 N. Miguel-Sancho, O. Bomatí-Miguel, G. Colom, J. P. Salvador, M. P. Marco and J. Santamaría, Chem. Mater., 2011, 23, 2795-2802.

3 N. Sozer and J. L. Kokini, Trends Biotechnol., 2009, 27, 82-89.

4 C. G. C. M. Netto, H. E. Toma and L. H. Andrade, J. Mol. Catal. B: Enzym., 2013, 85-86, 71-92.

5 C. W. Lim and I. S. Lee, Nano Today, 2010, 5, 412-434.

6 B. Lopez-Ruiz, E. Lopez Cabarcos and J. P. Hervas Perez, Stable biocompatible microgels for enzyme immobilization and its use in biosensors amperometricos, Spain patents, 2,320,078, 18 May 2009.

7 J. Qiu and S. Wang, Preparation method of double-enzyme glucose sensor based on graphene, China Patent, 1,030,33549, 17 December 2012.

8 J. Hou, G. Dong, B. Xiao, C. Malassigne and V. Chen, J. Mater. Chem. A, 2015, 3, 3332-3342.
9 C. Ji, J. Hou and V. Chen, J. Membr. Sci., 2016, 520, 869-880.

10 K. Bélafi-Bakó, M. Eszterle, K. Kiss, N. Nemestóthy and L. Gubicza, J. Food Eng., 2007, 78, 438-442.

11 L. Giorno and E. Drioli, Trends Biotechnol., 2000, 18, 339349.

12 A. Y. Gebreyohannes, M. R. Bilad, T. Verbiest, C. M. Courtin, E. Dornez, L. Giorno, E. Curcio and I. F. J. Vankelecom, J. Membr. Sci., 2015, 487, 209-220.

13 A. Y. Gebreyohannes, R. Mazzei, E. Curcio, T. Poerio, E. Drioli and L. Giorno, Ind. Eng. Chem. Res., 2013, 52, 10396-10405.

14 E. Bach and E. Schollmeyer, Anal. Biochem., 1992, 203, 335339.

15 J. V. Diaz, G. E. Anthon and D. M. Barrett, J. Agric. Food Chem., 2007, 55, 5131-5136.

16 Y. Sahoo, H. Pizem, T. Fried, D. Golodnitsky, L. Burstein, C. N. Sukenik and G. Markovich, Langmuir, 2001, 17, 79077911.

17 F. Militano, T. Poerio, R. Mazzei, E. Piacentini, A. Gugliuzza and L. Giorno, Colloids Surf., B, 2016, 143, 309-317.

18 S. K. Das, M. M. Khan, T. Parandhaman, F. Laffir, A. K. Guha, G. Sekaran and A. B. Mandal, Nanoscale, 2013, 5, 5549-5560.

19 J. Kim, J. W. Grate and P. Wang, Chem. Eng. Sci., 2006, 61, 1017-1026.

20 V. Mani, R. Devasenathipathy, S.-M. Chen, B. Subramani and M. Govindasamy, Int. J. Electrochem. Sci., 2015, 10, 691-700.

21 M. Zanoni, O. Habimana, J. Amadio and E. Casey, Biotechnol. Bioeng., 2016, 113, 501-512. 